\title{
Memory for intention-related material presented in a to-be-ignored channel
}

\author{
RichaRd L. MARSH \\ University of Georgia, Athens, Georgia \\ Gabriel I. CoOK \\ Claremont McKenna College, Claremont, California \\ J. Thadeus Meeks and Arlo Clark-Foos \\ University of Georgia, Athens, Georgia \\ AND \\ JASON L. HICKS \\ Louisiana State University, Baton Rouge, Louisiana
}

\begin{abstract}
Three experiments were conducted to investigate the fate of intention-related material processed in a to-beignored channel. Participants were given an intention to respond to cues in a visual-processing stream while simultaneously trying to ignore information being presented in an auditory stream. Subsequent to the ongoing activity, a surprise recognition test for information presented in the to-be-ignored auditory modality was administered. As compared with comparable neutral information, corrected recognition memory for intention-related material was significantly better, depending on the type of event-based prospective memory task. These results suggest that holding certain kinds of intentions can bias attentional processes in a manner consistent with a perceptual readiness for uptake of intention-related material.
\end{abstract}

Perhaps the most fundamental weakness of the cognitive system is its limited capacity to attend to only a very few elements of the physical or mental world at any given time (Kahneman, 1973; Norman \& Bobrow, 1975; Shiffrin \& Schneider, 1977). Numerous stimuli impinge on the cognitive system both from within and from without, and only a very few of them ever reach the level of conscious awareness and detailed cognitive processing. Of course, attention is a constant trade-off between focalization, on the one hand, and monitoring one's environment, on the other (Pashler, 1998); but the average cognitive psychologist has been inculcated to adopt William James's (1890/1950) definition as codified in the following wellknown excerpt from The Principles of Psychology:

Everyone knows what attention is. It is the taking possession by the mind, in clear and vivid form, of one out of what seem several simultaneously possible objects or trains of thought. Focalization, concentration, of consciousness are of its essence. (p. 261)

The question that is still debated today, over 100 years later, is how certain elements of our perceptual and mental worlds capture our attention and rise to the special status that we become "aware" of them. For some time, psychologists studying basic perceptual principles believed that certain singletons obligatorily captured attention, but we now know that top-down processing from goals and intentions largely determines what elements attract attention (e.g., Pashler, Johnston, \& Ruthruff, 2001). In the context of prospective memory, we have made the point that holding an intention to perform some activity may, therefore, determine what elements in our worlds are singled out for further processing (Hicks, Cook, \& Marsh, 2005). ${ }^{1}$

We are not the first to suggest that having an intention to perform some activity in the future may heighten awareness to intention-related material. In the post-World War II era of the New Look, psychologists studying perception argued that the intention to eat something because one is hungry heightens one's awareness of food-related objects and words (see Schiff, 1980, pp. 407-416). A good example of this was shown in a group of participants who were made to feel thirsty; they responded more quickly to drinking-related items in a lexical decision task than did a control group who had not been made to feel thirsty (Aarts, Dijksterhuis, \& De Vries, 2001). Recently, Goschke and Kuhl $(1993,1996)$ have argued that intentions reside in memory with an above-baseline level of activation, thereby biasing attention toward intention-related material. To use their example, if one has the intention to mail a letter, then mailboxes, mail trucks, stamps, enve-

R. L. Marsh, rlmarsh@uga.edu 
lopes, and post office fronts will capture attention more readily than they otherwise would if one did not have the intention. Goschke and Kuhl dubbed this idea the intention superiority effect. In our own work on the topic, people responded more quickly in a lexical decision task to intention-related words from to-be-performed scripts than to more neutral words that were not associated with an intention, and the same was true of partially completed but unfilled intentions (Marsh, Hicks, \& Bink, 1998). However, after an intention was completed (i.e., the script had already been performed), intention-related material was slightly inhibited, which we argued is ecologically adaptive insofar as it facilitates cognitive processing for the next activity that one wishes to undertake (Marsh et al., 1998; Marsh, Hicks, \& Bryan, 1999).

To date, all that has been shown in this literature is that intention-related material is processed more quickly. We have argued that the interpretation that intentions reside in memory with above-baseline activation may be wrong and that it may be the case that they are simply able to be revived more quickly (Marsh et al., 1998). In either case, these claims have been about the memorial status of intentions, and only Goschke and Kuhl (1996) and the New Look psychologists have implied that intentions affect attentional processing. Our goal in the present study was to develop a prospective memory paradigm that investigated the fate of material that was ostensibly unattended but, nevertheless, related to an active intention to perform an activity. If Goschke and Kuhl (1996) are correct that providing people with an intention heightens their attention toward intention-related material, it would be predicted that intention-related material that is processed in an unattended channel will elicit better memory performance later, as compared with otherwise equivalent material that is not related to the intention. ${ }^{2}$

We modeled our new paradigm on the older work concerning selective attention and dichotic listening (e.g., Broadbent, 1958; Cherry, 1953). In that early work, participants were told to shadow one ear and to ignore the material being played in the other ear. Of course, we now know that personally relevant material gains access from the unattended channel (e.g., Treisman, 1960; see also note 2). We reasoned that if Goschke and Kuhl (1996) are correct, intention-related material occurring in the unattended channel would gain access and be remembered later, as compared with equivalent material about which no intention has been formed. To do so, we used an event-based prospective memory task. The basic event-based paradigm busily engages participants in an ongoing activity and asks them to perform an action when intention-related material is encountered. For example, participants might be asked to respond overtly to animal words with a special keypress or a knock on the table (e.g., Einstein et al., 2005; Einstein, McDaniel, Williford, Pagan, \& Dismukes, 2003; Marsh, Hicks, \& Cook, 2005; McDaniel, Guynn, Einstein, \& Breneiser, 2004; McGann, Ellis, \& Milne, 2003). This paradigm has been used to ascertain what characteristics of the event-based cues and the processing task and what special populations affect cue detection (among other issues).

We modified the standard event-based paradigm, which usually involves processing a series of visual events on discrete trials (e.g., pictures, words, sentences, lexical decisions, etc.), by adding a concurrent auditory-processing stream that the participants were explicitly told to ignore. As such, the participants were engaged in an ongoing pleasantness-rating task on words seen in the center of the computer monitor, and they were told that the words heard over the computer speakers were designed to distract them and make their task more difficult. As a consequence, they were asked to do their best to ignore the words played auditorially and to expend all their effort on the pleasantness-rating task. Later, we gave them a recognition memory test for only the words played auditorially. Theoretically, if holding an intention - say, about detecting animal words in the pleasantness-rating task-heightens attentional awareness to intention-related material, animal words played in the to-be-ignored auditory channel should be detected more readily and remembered later, as compared with items from a comparable nonintention-related (control) category also presented auditorially.

\section{EXPERIMENT 1}

For participants given a categorical intention, half of them were given an intention to detect words denoting animals, and the other half were asked to respond to words denoting vegetables. The category not associated with the intention served as the control category. Words from both categories appeared in both the visual- and the auditory-processing streams. However, if having an intention to respond to one category biases attention toward intention-related material, a later memory test for those words should show higher corrected recognition, as compared with the control category. Three separate conditions were tested that differed as a function of the intention given. The first condition was a categorical intention as just described. The participants in a second condition were given an intention to respond either to four specific animals or to four specific vegetables. We were unclear whether having specific cues all related to the same category would bias attentional processing in the same way as having an intention about a category, but it was possible that trying to detect four specific cues would not bias attention at all. Finally, as a secondary control condition (above and beyond the control category), we tested four unrelated cues and placed a categorical associate in the to-be-ignored auditory-processing stream. If attention is biased only by having a categorical intention, the associate should not be detected as frequently as the to-beignored categorical information.

\section{Method}

Participants. Undergraduate students at the University of Georgia volunteered in exchange for partial credit toward a research appreciation requirement. The participants were tested individually in sessions that lasted approximately $25 \mathrm{~min}$. A total of 103 participants were haphazardly assigned to one of three conditions that differed as a function of the intention given. We had planned to test 34 people in each condition, but accidentally, an extra participant was tested in the four-unrelated-cues condition.

Materials and Procedure. The participants made pleasantness ratings on each of 100 trials of the ongoing task. Simultaneously with the visual presentation of a word, the participants heard another word played over the computer's speakers. All the words had 
been digitally recorded as sound files. Whether a word was heard or seen was randomly determined by the software. Of the 100 words seen by the participants, 4 words were from the category related to their intention, and 4 were drawn from the control category (either animals or vegetables); these words were randomly assigned to specific ongoing activity trials. There were 12 items in the word pool for the animal and vegetable categories. Four had been designated as to-be-seen items, 4 were designated as to-be-heard items, and 4 were designated as lures on the later recognition memory test. These subsets of 4 words were roughly equated for word frequency. To disguise the nature of the task, we also placed four vehicles and four musical instruments in the visual-processing stream; likewise, we placed four articles of clothing and four body parts in the auditory stream. This action was taken to prevent the animals and the vegetables from being the only categorized items on the list. The remaining 84 items in each of the visual- and the auditory-processing streams were chosen randomly from a list of 168 items that were not related to the animal or vegetable categories (and not related to each other). Each word remained on the screen until a judgment had been made, which, in our experience, has been approximately $3 \mathrm{sec}$.

The participants read instructions for their assigned condition from the computer monitor; then the experimenter cleared the screen and verbally reiterated them. These instructions stressed that the auditory words were designed to be distracting and that the participants should try very hard to ignore them because they were irrelevant to their main task of making pleasantness ratings. In the cases in which specific words were given as event-based cues, the experimenter did not proceed with the experiment until the participants could repeat back the four cues. In a small number of cases, the experimenter had to repeat back the cues and ascertain that the participants had committed them to memory. In the related specific cues conditions, when the intention was about animals, the cues were $d o g$, lion, tiger, and sheep; when it was about vegetables, the words were peas, onion, carrot, and corn. Obviously, these were the same words as those used as event-based cues in the categorical intention conditions. In the unrelated specific cues condition, the four cues were $d o g$, knife, apartment, and valley (and the categorical associates heard were lion, pan, cabin, and canyon, taken from Nelson, McEvoy, \& Schreiber, 1998).

For readers unfamiliar with the Battig and Montague (1969) category norms, one metric of the frequency ascribed to items is the number of participants who listed a particular item. All of the quadruplets presented in the visual and auditory streams, as well as those used as lures on the recognition test, were listed, on average, by 150-225 people. This frequency places all the items used in the high output dominance category and makes them strong associates in a category-listing task. However, when the cue, control, and lure items are examined according to Nelson et al.'s (1998) free association norms, the mean backward and forward association values to the category name and to each other (when listed) for these quadruplets of words are, on average, rather low, in the range of .01-.07. This is true of all the items used in all the conditions. So, by a metric of free association, the items are neither strong forward nor strong backward associates to their category label, which strengthens our position against any argument that the items in the unrelated-cues conditions are somehow fundamentally different in association strength from those drawn from a single semantic category. However, we do acknowledge to the reader that the category-listing and free association tasks tell us rather different things.

The visually presented event-based cues were placed at Trials 23 , 48,73 , and 98 . The intention-related material to be ignored never appeared on these trials but, rather, occurred on Trials 15, 35, 60, and 85 . Consistent with many of our studies, the participants were asked to press the "/" key to event-based cues and then make their pleasantness rating. After the ongoing task had been explained and the experimenter was confident that the participants understood the intention, a 3-min distractor task was given to prevent the prospective memory task from becoming a vigilance task. Upon concluding that activity, the experimenter commenced the ongoing task without any reference to the prospective memory task. In this experiment and those that follow, the participants were never given any information about the control categories.

Upon concluding the ongoing activity, the participants read instructions for the recognition test from the computer monitor. When they indicated that they understood them, the experimenter cleared the monitor and verbally repeated them. The participants were asked to respond old if the word had been presented auditorily and new if the word was brand new. Nothing presented visually during the ongoing task was tested. Rather, the recognition test consisted of only 32 items. Sixteen of these items were the 4 intention-related items that had been presented auditorially, the four distractors from that category, the 4 items from the control category that were presented auditorially, and the four lures from that category. The remaining 16 items were 4 auditorially presented items and four lures from each of the categories of articles of clothing and body parts.

\section{Results and Discussion}

Unless otherwise specified with an explicit $p$ value, the probability of a Type I error does not exceed the conventional level of $5 \%$. For the main results, we will report only a measure of corrected recognition for the intention-related and control categories (i.e., hits minus false alarms). Performance of the other items on the test list mimicked that of the control categories. Moreover, the false alarm rates were in the $10 \%-20 \%$ range, and the results and interpretation of this experiment (and those that follow) do not hinge critically on whether the raw hit rate or the corrected measure is used to assess performance. Consequently, we prefer the latter, because it corrects for any potential bias that might come from testing only on categorically related items. In calculating these corrected measures, we subtracted from the intention-related hits the intention-related false alarms and did the same (separately) for the control items. Concerning the false alarm rates, there was no systematic relationship between the intention-related and the control false alarms across the three experiments. Sometimes the control false alarm rate exceeded that of the intention-related false alarms, and sometimes it went in the opposite direction. Because the results did not differ appreciably with an intention about animals versus vegetables, we have pooled over these counterbalancing conditions (for a similar outcome, see Marsh, Hicks, \& Watson, 2002, Experiment 1). Finally, no participant in this experiment or those that follow false alarmed and responded to the intention-related material presented auditorially.

The top portion of Table 1 summarizes the proportion of cues detected and corrected recognition memory performance. A one-way ANOVA on the proportion of cues detected during the pleasantness rating task verified that specific cues led to better event-based prospective memory, $\left[F(2,100)=6.43, \eta_{\mathrm{p}}^{2}=.11\right]$. This finding has been reported before (e.g., McDaniel \& Einstein, 1993; Ellis \& Milne, 1996), as when an intention related to animals resulted in lower cue detection than did an intention about lion, leopard, and tiger. Thus, this outcome is not surprising, but the conceptual replication is nonetheless reassuring. Recognition memory was analyzed with a 2 (item: intention-related or control category) $\times 3$ (intention: categorical, specific related cues, or specific unrelated cues) mixed model ANOVA. The interaction indi- 
Table 1

Event-Based Cue Detection and Corrected Recognition Memory for Intention-Related and Control Words Presented in the Unattended (Auditory) Channel

\begin{tabular}{|c|c|c|c|c|c|c|}
\hline \multirow[b]{3}{*}{ Condition } & & & \multicolumn{4}{|c|}{$\begin{array}{c}\text { Corrected } \\
\text { Recognition Memory }\end{array}$} \\
\hline & \multicolumn{2}{|c|}{$\begin{array}{c}\text { Prospective } \\
\text { Memory }\end{array}$} & \multicolumn{2}{|c|}{$\begin{array}{c}\text { Intention } \\
\text { Related }\end{array}$} & \multicolumn{2}{|c|}{$\begin{array}{c}\text { Control } \\
\text { Category }\end{array}$} \\
\hline & $M$ & $S E M$ & $M$ & $S E M$ & $M$ & $S E M$ \\
\hline \multicolumn{7}{|c|}{ Experiment 1} \\
\hline Categorical & .66 & .05 & .38 & .05 & .22 & .05 \\
\hline Specific related cues & .85 & .03 & .32 & .05 & .19 & .05 \\
\hline Specific unrelated cues & .82 & .04 & .19 & .05 & .24 & .05 \\
\hline \multicolumn{7}{|c|}{ Experiment 2} \\
\hline Breakfast foods & .71 & .06 & .45 & .05 & .29 & .06 \\
\hline Foods & .61 & .06 & .44 & .05 & .26 & .05 \\
\hline \multicolumn{7}{|c|}{ Experiment 3} \\
\hline Prime control category & .55 & .05 & .28 & .05 & .29 & .05 \\
\hline Context-linked intention & .00 & .00 & .21 & .05 & .23 & .05 \\
\hline
\end{tabular}

cated that performance was qualitatively different in the first two conditions (category and specific related cues), as compared with the four specific unrelated cues condition $\left[F(2,100)=3.96, \eta_{\mathrm{p}}^{2}=.07\right]$. The participants who had the unrelated-cues intention did not detect categorical associates of those words in the unattended channel $[t(34)=1.05$, n.s. $]$. By contrast, having either a categorical intention or one about four specific cues from the same category was sufficient to bias attention toward that information in the auditory channel, because recognition memory was higher for the intention-related words than for the control category. This outcome is demonstrated by the main effect in the ANOVA model $[F(1,100)=$ $\left.5.14, \eta_{\mathrm{p}}^{2}=.05\right]$, as well as by individual simple effects for intention-related material, as compared with the control material [smaller of the two $t(33) \mathrm{s}=2.03, p=.05$ ]

In the literature on the intention superiority effect, participants have learned scripts of five or six actions (e.g., polish the glass, distribute the cutlery, etc.). If there was an intention to perform that script, the participants made faster decisions to those words (polish, glass, distribute) than to words from a comparably learned script about which there was no intentionality. That effect was found for words that were actually studied in the task. By contrast, the effect found here was for unstudied intention-related words, not for words relevant to the ongoing task itself. To our knowledge, this is the first demonstration that having an intention can bias attention toward intention-relevant material. This outcome occurred even when the participants were supposed to respond to four specific (but related) category members. Whether the participants slightly reformulated the intention into a categorical intention is unclear from these data. There was a nominal but not statistically significant lower rate of recognition of the intention-related words in that condition. However, because the related specific cues condition acted more like the categorical intention condition in terms of recognition performance, the participants probably did reformulate their intention. Nevertheless, the outcome of this experiment is clear: Having an intention can cause intention-related material to be noticed and processed despite strong instructions to ignore that information.

\section{EXPERIMENT 2}

As with any novel finding, a conceptual replication was needed to verify that it is the true state of affairs. Consequently, in this next experiment, we gave people an intention to respond either to foods or to breakfast foods. In actual fact, all of the food words were breakfast foods. We did so because Cook, Marsh, and Hicks (2007) found that people had a higher cue detection rate when given the more specific intention to respond to rodents rather than to animals, even though all of the cues were rodents. Although the previous experiment did not show a specificity effect in recognition memory performance (four specific animals vs. the category animals), we used the food-related intentions because it was an alternative way of manipulating the specificity of the intention while still keeping both intentions categorical. If the results from Experiment 1 reflect a biasing of attention toward intention-related material, both conditions used here may show greater recognition memory for food-related items presented in the tobe-ignored auditory channel, as compared with a control category that has no associated intentionality. The effect, however, may be greater for the breakfast food intention, because it has somewhat greater specificity (the results from Experiment 1 notwithstanding).

\section{Method}

Participants. Undergraduates from the University of Georgia volunteered in exchange for partial credit toward a research appreciation requirement. The participants were tested individually in sessions that lasted approximately $25 \mathrm{~min}$. The participants were assigned to the two intention conditions by switching in alternation between them. Each condition consisted of 35 participants; in total, 70 were tested.

Materials and Procedure. The procedure for this experiment was virtually identical to the categorical intention condition used in Experiment 1 . The only difference was that to match word frequencies and other standard learning variables of the 12 breakfast foods, a new control condition (musical instruments) had to be chosen; then new sound files had to be recorded from the same person who had performed this activity earlier. The names of the 12 breakfast foods were vetted in-house to ensure that everyone that we asked agreed that every item on the list was a breakfast food. Obviously, we could not counterbalance the control and prospective categories as we did in Experiment 1. Therefore, depending on their assigned condition, the participants received instructions to respond either to foods or to breakfast foods and were given no information about musical instruments. Otherwise, the procedure was identical to that in Experiment 1, down to roughly matching the word frequencies and other variables of the breakfast foods that were seen, heard, and used as lures on the recognition test (and the same was done for the musical instruments control category).

\section{Results and Discussion}

The results are presented in the middle of Table 1. Cue detection was nominally higher in the breakfast food condition than in the food intention condition, but this difference was not statistically significant $[t(68)=1.22$, n.s.]. That outcome was consistent with the direction of the (statistically significant) average cue detection per- 
formance that Cook et al. (2007) found using rodent and animal intentions. Vast differences in the procedures in the two studies may account for the differences in eventbased cue detection. Alternatively, the distinction between a breakfast food and other foods may have a blurrier set of boundary conditions than does the distinction between an animal and a rodent, which has a more scientific basis for the boundary conditions.

Corrected recognition of the breakfast foods and control items presented in the auditory channel was analyzed using a 2 (intention: foods or breakfast foods) $\times 2$ (item: intention related or control) mixed model ANOVA. Only the main effect of item was statistically significant $[F(1,68)=$ $\left.10.40, \eta_{\mathrm{p}}^{2}=.13\right]$, indicating that intention-related material about foods was detected in the auditory channel to a greater extent than was material about musical instruments. As such, this experiment replicated Experiment 1 in showing that having an intention can bias attention toward intention-related material, at least with a categorical intention. We found no evidence of an intention specificity effect in which the breakfast food intention heightened awareness of those items in the auditory-processing stream above and beyond a food intention. Regardless, these two conditions replicated those for the categorical and four specific related cues tested in Experiment 1, thereby indicating that the effect found in Experiment 1 is probably a more general attentional biasing phenomenon.

\section{EXPERIMENT 3}

Having demonstrated the basic effect in four separate conditions, we sought to extend our understanding of those conditions in which attention is not directed toward intention-related material in the to-be-ignored channel. Experiment 1 yielded one such condition, insofar as having an intention about four specific unrelated cues did not draw attention to their associates in the unattended channel. In this next experiment, we wanted to ascertain whether linking the event-based intention to a distal context would eliminate the attentional capture of intentionrelated material. Recently, Marsh, Hicks, and Cook (2006) demonstrated that no task interference was experienced over an intervening context if the event-based or timebased intention was linked to a context that was expected to occur after the ongoing task had been concluded. Task interference is the lengthening of latencies that occurs in an ongoing task because attention is partially divided between the ongoing and a prospective memory task. In those experiments, the participants experienced three distinct phases of the experiment. If the intention was linked to a third phase after the second phase (a demographic questionnaire), no task interference occurred in the first phase, because the participants were not yet in the performance context and, presumably, the intention was not active during the first phase. We predicted that linking the intention to a future, third phase of the experiment might affect the detection of intention-relevant material during the first phase (i.e., the ongoing pleasantness ratings tested in Experiments 1 and 2). More specifically, we predicted that if the intention was not active, the intention-related material would not capture attention, thereby eliminating the recognition memory advantage observed in Experiments 1 and 2 .

In another condition, we tested Ellis and Milne's (1996) idea that with categorical intentions, participants might sample members of the category at intention formation. They argued that this self-priming process helps participants to detect high output dominance exemplars, but not less central category members, in terms of event-based prospective memory performance. If this sort of activity contributes to the attentional capture of intention-related material, we should be able to remove the advantage by priming the control category. By having participants write down items from the control category of vegetables, we predicted that attentional awareness for non-intention-related items in the to-be-ignored channel might be heightened. If so, the difference in recognition memory between the intention-related material and the control category should be attenuated or even eliminated. Obviously, these two conditions - a context-linked intention and the priming of a control category - do not hang together conceptually as a unified experiment, but together they converge as ways to attenuate the effects found in Experiments 1 and 2. Thus, both conditions place important boundary conditions on the novel effect that we are studying. Rather than label them Experiments $3 \mathrm{~A}$ and 3B, for brevity we have simply reported them together as a single experiment.

\section{Method}

Participants. University of Georgia undergraduates volunteered in exchange for partial credit toward a research appreciation requirement. The participants were tested individually in sessions that lasted approximately $25 \mathrm{~min}$. Thirty-five volunteers were tested in each of the priming and the context-linked intention conditions.

Materials and Procedure. The two conditions in this experiment were virtually identical in their essential properties to those already described with a categorical intention, except in the following respects. In the priming condition, the experimenter handed the participants a blank piece of paper and a pencil, along with the request that they list all of the vegetables (the control category) that they could in $30 \mathrm{sec}$ as timed with a handheld stopwatch. After removing the paper, the instructions for the pleasantness-rating task and the intention were given just as in the conditions reported in Experiments 1 and 2 (i.e., the intention was active during the pleasantness-rating task).

In the context-linked condition, we told the participants that the experiment consisted of three distinct phases. In the first, they would have to make pleasantness ratings and ignore auditorially presented information. In the second, they would have to answer a brief demographic questionnaire; and in the third, they would have to make judgments of syllabic length. They were given the intention to respond to animal words, but only when they reached the syllable-counting phase (i.e., the same intention as that used by Marsh et al., 2006). Therefore, the intention should not be activated during the pleasantness-rating task, because the performance interval was linked to the syllablecounting task. In actual fact, the participants never performed the demographic questionnaire and the syllable-counting task; rather, they went straight from the pleasantness-rating task into the instructions for the recognition memory task for the to-be-ignored information. We used a single control category (and intention category) because Experiment 1 showed no differences in the counterbalancing conditions. Subsequent to clearing the computer monitor and reiterating the instructions, the distractor ensued, and then the ongoing task was commenced without any mention of the prospective memory task. In all other respects, these two conditions were procedurally identical to each other and those already reported. 


\section{Results and Discussion}

The results are summarized at the bottom of Table 1 . Event-based cue detection in the priming condition was $55 \%$, whereas in the context-linked condition, no one erroneously responded to the animal cues in the pleasantnessrating task. Therefore, we have placed $0 \%$ in Table 1 as a place marker, although the participants should not have responded in that phase. As was predicted from Ellis and Milne's (1996) theory, priming the control category raised corrected recognition memory to the level of awareness of the intention-related material in the to-be-ignored channel $[t(34)<1$, n.s. $]$. However, the careful reader will note that recognition memory for the intention-related material was slightly lower than it was in the previous two experiments. Although the general outcome of no difference was predicted on the basis of Ellis and Milne's theory, we suspect that activating the control category of vegetables somehow deactivated the intention-related animal category. Such an outcome is consistent with Anderson's ACT-R model, in which there is a limited amount of activation that must be divided among activated entities, as was discussed in the introduction herein (see Anderson et al., 2004). The fact that event-based cue detection was nominally the lowest among all of the conditions tested in this study is also consistent with the animal intention's not receiving as much activation as it did in the previous two experiments.

We also predicted that corrected recognition memory would be the same for the two classes of material in the context-linked condition. Indeed, recognition memory did not differ $[t(34)<1$, n.s.]. That outcome strongly suggests that the biasing of attention toward intention-related material will occur only when the intention is activated during a performance interval, but not when the intention is held in abeyance and the intended activity is linked to a distal context that has not yet arrived. Together, the two conditions tested in this experiment suggest that holding an intention activates intention-related material, which can bias attention toward that material in an unattended channel, but only when the intention is active. We will turn now to placing the results from all three experiments into the theoretical fabric of work on prospective memory.

\section{GENERAL DISCUSSION}

We undertook this investigation to ascertain whether intention-related material is perceived differently from comparable information that has no associated intentionality. We chose the approach of asking whether tobe-ignored material (that was or was not related to the intention) can be identified later as having been experienced (i.e., recognized). The answer to our question seems to be that material related to an intention is more readily perceived and retained by the cognitive system, at least with certain kinds of prospective memory tasks. With a categorical intention or with the goal of detecting specific cues from the same category, intention-related material appears to receive privileged processing, as measured by a later recognition memory task. The results from the context-linked intention in Experiment 3 argue very strongly that one must be in the performance interval or otherwise have the intention activated for this outcome to occur. Otherwise, intention-related material receives no privileged access via attentional mechanisms.

We described the intention superiority effect earlier and how that literature bears on the present investigation. In those studies, participants acquired pairs of scripts to criterion learning. If one of those scripts needed to be performed later, decision latencies were shorter to words from that script than to those from the neutral script. Marsh et al. (1998) claimed that the activation level of the to-be-performed script was being measured relative to the more neutral script. Because the amount of available activation was fixed at given point in time (Anderson, 1983), if the intention to perform the script accrued activation, it basically borrowed activation from the more neutral material. This argument bears more than a passing resemblance to the current debate about whether holding an intention causes task interference to the ongoing task itself (e.g., Einstein et al., 2005; Marsh et al., 2005). As was mentioned earlier, certain kinds of prospective memory tasks evidence longer reaction times to the ongoing activity itself, as compared with having no intention at all. Like Marsh et al.'s (1998) claim, when there is a fixed amount of mental energy available for a particular task set, adding a prospective memory task will potentially usurp the activation available to perform the ongoing task (thereby increasing decision latencies). The primary difference between the two paradigms (script learning and the present investigation) is that in the present project, we are essentially measuring activation for related material, and not for the material previously presented in the experiment. Therefore, we have shown a sort of perceptual readiness for material that is related to a prospective memory task (e.g., Aarts et al., 2001; Bruner, 1957).

A trenchant critic might argue that all we have shown is perceptual readiness that comes in the form of priming. After all, Ellis and Milne (1996) claimed that participants who are given a categorical intention might sample memory for members of that category during intention formation. Consistent with that interpretation, the participants who were asked to briefly list some vegetables prior to making their pleasantness rating in Experiment 3 correctly reported remembering more vegetables in the to-be-ignored auditory channel (a claim that we make via a cross-experimental comparison that is nominally, but not statistically, significant). Because that category was not associated with an intention, by inference, forming a prospective memory might involve thinking of related materials, which are then primed for later perception (i.e., perceptual readiness). There are several problems with such an oversimplification. First, a priming explanation does not account for performance in the context-linked condition in Experiment 3. Presumably, those participants would also have sampled memory for category items during intention formation in the same manner as the participants tested in Experiments 1 and 2. However, they remembered very few of the intention-related items presented in the auditory channel. Consequently, mere priming cannot account for the full spectrum of outcomes. 
Second, we have queried our participants at various points over the years in our prospective memory work, and they have not reported that they tried to sample memory for the kinds of animals, fruits, clothing, foods, or furniture that we have used as categorical intentions. We do not deny that the category label itself primes highly typical exemplars. But the third prong in our rebuttal is that such priming effects are relatively short-lived (one or two trials in a semantic-priming task; e.g., Meyer \& Schvaneneldt, 1971) and we cannot fathom how they would survive over a 3-min filled distractor interval specifically designed to deactivate the intention itself. Fourth and finally, if this were merely a priming phenomenon, the more specific breakfast food intention should have resulted in more tobe-ignored items being detected, as compared with the food condition, but this outcome was not observed.

Rather, we believe that exposure to a category, or a set of related items essentially forming a category, causes that category representation to remain activated, but not the exemplars themselves that are sampled from memory (if they are even sampled). Having a category heightened in activation provides a perceptual or conceptual readiness to process items consistent with that concept. Our preferred model for explaining such effects is Cowan's (1995) model of working memory. In that model, about four items receive sustained activation. Items not currently receiving focal attention reside just outside the metaphorical focus of attention. Their representations, however, are still far above baseline activation and still can influence focal processing, even though they currently reside outside the focus of attention. If this is what happens to a categorical representation after it is activated, forming an intention to respond to animals or listing a few vegetables are both activities that activate their category representations. Both activities cause the person be in a state of readiness for related material from those categories. In the case of providing four unrelated specific cues, no categorical representations are strongly activated, and so, no intention-related material receives extra attention when it is perceived later. In explaining why cue detection is better with specific cues than with categorical intentions, one need look no further than to the fact that the item itself is a perfect copy cue of what was studied during intention formation; therefore, it has a higher probability of causing the intention to come to mind when it is processed.

We believe that intentions about an activity bias attention toward materials consistent with performing that activity. For example, in time-based prospective memory tasks, people form the intention to perform an activity at a specific time. Extrapolating from the present results to that prospective memory task, one should more readily perceive a novel clock or one's wristwatch catching a shirt sleeve, and those perceptions should cause the intention to come to mind. Not many of us think about a watch, a clock, or a shirt sleeve when forming a time-based intention, but should those external events eventually be found to be more readily perceived, as compared with neutral events, a mere priming explanation of specific concepts (e.g., dog, tiger) for the present results would most certainly be even more untenable than we have already argued it is. Nevertheless, there appears to be both an upside and a downside to the attentional bias toward material consistent with (or associated with) an intention. On the positive side, more cues are perceived and potentially noticed, and this can serve to keep intentions fresh, thereby potentially increasing the probability that they will be fulfilled. On the negative side, current ongoing activities can be interrupted with thoughts of uncompleted intentions (i.e., stimulus-independent thoughts), and these could have a slightly deleterious effect on one's current performance. Which of these effects is more dominant in everyday life is unclear, but we hope that the attentional bias to process information that comes from holding an intention actually increases the probability of intention completion.

\section{AUTHOR NOTE}

We thank Brannan McDougald, Mary Lee, Stacia Fink, and Jenny Hand for their dedicated help in collecting the data. We also thank Gil Einstein, Judi Ellis, Neil Mulligan, and an anonymous reviewer for helpful feedback on an earlier version of the manuscript. The origins of this article came from a joke, so the authors find science even in humor. Correspondence concerning this article should be addressed to R. L. Marsh, Department of Psychology, University of Georgia, Athens, GA 30602-3013 (e-mail: rlmarsh@uga.edu).

\section{REFERENCES}

Aarts, H., Dijksterhuis, A., \& De Vries, P. (2001). On the psychology of drinking: Being thirsty and perceptually ready. British Journal of Psychology, 92, 631-642.

ANDERson, J. R. (1983). The architecture of cognition. Cambridge, MA: Harvard University Press.

Anderson, J. R., Bothell, D., Byrne, M. D., Douglass, S., Lebiere, C., \& QIN, Y. (2004). An integrated theory of the mind. Psychological Review, 111, 1036-1060.

Battig, W. F., \& Montague, W. E. (1969). Category norms for verbal items in 56 categories: A replication and extension of the Connecticut category norms. Journal of Experimental Psychology Monographs, 80, 1-46.

Broadbent, D. E. (1958). Perception and communication. New York: Pergamon.

Bruner, J. S. (1957). On perceptual readiness. Psychological Review, 64, 123-152.

Cherry, E. C. (1953). Some experiments on the recognition of speech, with one and with two ears. Journal of the Acoustical Society of America, 25, 975-979.

Cook, G. I., Marsh, R. L., \& Hicks, J. L. (2007). The nature of categorical cues in event-based prospective memory tasks. Unpublished manuscript.

Cowan, N. (1995). Attention and memory: An integrated framework. New York: Oxford University Press.

Einstein, G. O., McDaniel, M.A., Thomas, R., Mayfield, S., Shank, H., Morrisette, N., \& Breneiser, J. (2005). Multiple processes in prospective memory retrieval: Factors determining monitoring versus spontaneous retrieval. Journal of Experimental Psychology: General, 134, 327-342.

Einstein, G. O., McDaniel, M. A., Williford, C. L., Pagan, J. L., \& DisMUKES, R. K. (2003). Forgetting of intentions in demanding situations is rapid. Journal of Experimental Psychology: Applied, 9, 147-162.

Ellis, J., \& Milne, A. (1996). Retrieval cue specificity and the realization of delayed intentions. Quarterly Journal of Experimental Psychology, 49A, 862-887.

Goschke, T., \& Kunl, J. (1993). Representation of intentions: Persisting activation in memory. Journal of Experimental Psychology: Learning, Memory, \& Cognition, 19, 1211-1226.

GoschKe, T., \& KuHL, J. (1996). Remembering what to do: Explicit and implicit memory for intentions. In M. Brandimonte, G. O. Einstein, \& M. A. McDaniel (Eds.), Prospective memory: Theory and applications (pp. 53-91). Hillsdale, NJ: Erlbaum. 
Hicks, J. L., Cook, G. I., \& Marsh, R. L. (2005). Detecting event-based prospective memory occurring within and outside the focus of attention. American Journal of Psychology, 118, 1-11.

JAMES, W. (1950). The principles of psychology. New York: Dover. (Original work published 1890)

Kahneman, D. (1973). Attention and effort. Englewood Cliffs, NJ: Prentice-Hall.

Lachter, J., Forster, K. I., \& Ruthruff, E. (2004). Forty-five years after Broadbent (1958): Still no identification without attention. Psychological Review, 111, 880-913.

MARsh, R. L., Hicks, J. L., \& BinK, M. L. (1998). The activation of completed, uncompleted, and partially completed intentions. Journal of Experimental Psychology: Learning, Memory, \& Cognition, 24, 350-361.

Marsh, R. L., Hicks, J. L., \& BRyan, E. S. (1999). The activation of unrelated and cancelled intentions. Memory \& Cognition, 27, 320-327.

Marsh, R. L., Hicks, J. L., \& CoOK, G. I. (2005). On the relationship between effort toward an ongoing task and cue detection in event-based prospective memory. Journal of Experimental Psychology: Learning, Memory, \& Cognition, 31, 68-75.

Marsh, R. L., Hicks, J. L., \& CoOK, G. I. (2006). Task interference from prospective memories covaries with contextual associations of fulfilling them. Memory \& Cognition, 34, 1037-1045.

Marsh, R. L., Hicks, J. L., \& WATSON, V. (2002). The dynamics of intention retrieval and coordination of action in event-based prospective memory. Journal of Experimental Psychology: Learning, Memory, \& Cognition, 28, 652-659.

McDaniel, M. A., \& Einstein, G. O. (1993). The importance of cue familiarity and cue distinctiveness in prospective memory. Memory, 1, 23-41.

McDaniel, M. A., Guynn, M. J., Einstein, G. O., \& Breneiser, J. (2004). Cue-focused and reflexive-associative processes in prospective memory retrieval. Journal of Experimental Psychology: Learning, Memory, \& Cognition, 30, 605-614.

McGann, D., Ellis, J., \& Milne, A. (2003). Conceptual and perceptual processing in prospective remembering. European Journal of Cognitive Psychology, 15, 19-41.

Meyer, D. E., \& SchVAneneldt, R. W. (1971). Facilitation in recognizing pairs of words: Evidence of a dependence between retrieval operations. Journal of Experimental Psychology, 90, 227-234.

Nelson, D. L., McEvoy, C. L., \& Schreiber, T. A. (1998). The University of South Florida word association, rhyme, and word fragment norms. Available at www.usf.edu/FreeAssociation.
Norman, D. A., \& Bobrow, D. G. (1975). On data-limited and resourcelimited processes. Cognitive Psychology, 7, 44-64.

PASHler, H. E. (1998). The psychology of attention. Cambridge, MA: MIT Press.

Pashler, H. [E.], Johnston, J. C., \& Ruthruff, E. (2001). Attention and performance. Annual Review of Psychology, 52, 629-651.

ScHIFF, W. (1980). Perception: An applied approach. Boston: Houghton Mifflin.

Shiffrin, R. M., \& Schneider, W. (1977). Controlled and automatic human information processing: II. Perceptual learning, automatic attending, and a general theory. Psychological Review, 84, 127-190.

Treisman, A. (1960). Contextual cues in selective listening. Quarterly Journal of Experimental Psychology, 12, 242-248.

\section{NOTES}

1. Some readers probably would prefer us to have couched our arguments in terms of peripheral versus central attention. According to that distinction, peripheral attention selects stimuli for later processing, whereas central attention controls memory and task management. However, we prefer the more common terminology of bottom-up versus top-down processing, which corresponds roughly to perceptual analysis versus the influence of the real world, semantic knowledge, and current goals in guiding perception. Because having an intention aligns more closely with having a goal, we prefer this framing of our arguments.

2 . Throughout this article, we use the terms unattended channel and to-be-ignored channel synonymously, although the latter probably best describes the true state of affairs. Recently, Lachter, Forster, and Ruthruff (2004) have argued that many of the previous studies in which such phenomena as dichotic-listening tasks (and others containing an unattended channel) have been investigated probably did not do the best job of ensuring that the channel actually received very little to no attention. Rather, participants could covertly switch their attention to the unattended channel. Our experiments are no less subject to such a criticism, and consequently, the reader should feel free to consider this a relative manipulation in which more attention is devoted to the attended channel, whereas less attention is devoted to the to-be-ignored channel. This issue in no way weakens the theoretical propositions being proffered.

(Manuscript received December 21, 2005; revision accepted for publication June 11, 2006.) 